\title{
LA MINERIA DEL CARBON Y DEL HIERRO EN LA RIOJA DURANTE EL SIGLO XIX \\ (Breve introducción histórica)
}

Tomás Franco Aliaga*

\section{Introducción}

La Revolución Industrial de finales del siglo XVIII se sustenta sobre dos columnas hercúleas, el hierro y el carbón. Pero es este último, convertido en energía mineral, el que condiciona los ritmos de crecimiento de las industrias y su localización, no exenta de un marcado determinismo en las primeras décadas.

La Sociedad se transforma radicalmente en numerosos órdenes, sus estructuras seculares se tambalean y la población activa, adscrita durante milenios a la agricultura, se agolpa desordenadamente en las explotaciones mineras y ante los portalones de las nuevas industrias.

Ingentes masas humanas abandonan los campos para hacinarse en suburbios sórdidos; se quiebran las relaciones sociales alimentadas por la tradición, la familia de largo parentesco, la autoridad paterna; la producción en masa arrolla a la artesanía de series casi numeradas y se inicia una carrera desenfrenada hacia el consumo indiscriminado, no viéndosele otro freno que el agotamiento de los recursos, si antes no sucumbe esta sociedad por la contaminación imparable o por la destrucción violenta.

\section{Condiciones de explotación}

El valor de una explotación minera está en función de los medios

* Departamento de Geografía. Colegio Universitario de La Rioja. Logroño. 
técnicos de que se dispone y de sus condiciones físicas, como profundidad de la masa explotada, permeabilidad, continuidad estrati gráfica de las aglomeraciones, calidad del producto, etc. ${ }^{1}$.

De ahí que cuando los gastos de explotación son muy elevados y el producto se encuentra más barato en los mercados internacionales, si no existen otras razones más poderosas de carácter político o estratégico, se cierra la mina definitivamente o a la espera de una coyuntura técnica o de mercado más favorable.

Conviene insistir, pues, con P. George que "la apreciación cualitativa del producto obtenido debe ser considerada solamente en relación con el contexto técnico del momento, susceptible siempre de ser mejorado"2, aunque me atrevería a llevar más lejos las palabras del geógrafo francés, insistiendo en que no basta el "contexto técnico" sino que son también decisivas las circunstancias sociopolíticas, el precio del mineral, las condiciones rígidas en el desarrollo regional, el aprovechamiento "in situ" etc., para modificar el interés económico sobre un determinado yacimiento.

La aparición de los hidrocarburos, primeramente, y la de otras fuentes de energía atómica, ya consolidada, y la solar, en ciernes, han dado al traste con la hegemonía del carbón. Con todo, estamos asistiendo a una nueva recuperación del mismo por motivos dispares como la subida vertiginosa del precio del petróleo y la contestación masiva de grupos ecologistas a las centrales nuçeares, cuya proverbial seguridad se ha tambaleado tras reiterados y graves accidentes.

En España, el carbón no se ha visto favorecido ni por la geología ni por la calidad, pues posee escasa potencia calorífica y un abundante porcentaje de cenizas y azufre. Sólo en reducida proporción es coqueficable. A ello hay que añadir la estrechez y dislocación de las capas con una media de 50-60 centímetros, frente a los dos metros de muchos yacimientos ingleses o alemanes, lo que hace poco rentable la maquinaria de alta y costosa tecnología. Aún hay más: su limpieza es escasa y posee un alta proporción de menudos que, por las dificultades del mercado, exige su consumo a boca-mina, en centrales térmicas o en la construcción de briquetas ${ }^{3}$.

1. George, P. “Geografía Económica” Ariel, Madrid 1970, pág. 107. Tamames, R. "Estructura Económica de España" Alianza Ed., Madrid, 1978, $12^{\circ}$ Edic., pág. 396.

2. Ibid., pág., 110.

3. Tamames, R. op. cit., pág. 396. 
En estas condiciones, nuestro carbón ha resultado costoso y de calidad mediocre y su producción se ha mantenido y aún acrecentado hasta 1965 bajo una fuerte protección estatal.

\section{El carbón riojano o las fantasías de un ingeniero}

Hasta 1878, los carbones de la provincia figuraban en las Estadísticas Mineras como lignitos, pero se demostró que "mediante la determinación de los vegetales fósiles que los acompañaban"4 correspondían al período carbonífero $\mathrm{y}$, por su enorme potencial calorífico, podían clasificarse como verdaderas hullas.

\section{Préjano}

Sobre la explotación de los carbones de Préjano poseemos conocomientos desde el 6 de septiembre de 1609, fecha en que se extiende una carta en favor de D. Pedro de León, y D. Juan Sánchez Vallejo ${ }^{5}$. Del año 1785 contamos con una información curiosa: los médicos del entorno declaran el carbón nocivo para los herreros y para el vecindario en general. Su uso queda prohibido con gran satisfacción de las gentes, pues ya desde siempre los obreros habian puesto grandes reparos a trabajar en las minas consideradas como puertas del infierno, temiendo verse arrastrados hacia allí en cualquier momento. Las emanaciones de gas, los malos olores, algunos accidentes graves y las explosiones de grisú hicieron el resto en la fantansía popular ${ }^{6}$.

Ya de lleno en el siglo XIX, el carbón de Préjano va adquiriendo cierta importancia, dentro de un marco reducido, entre las industrias de los pueblos cercanos. Sirvan de ejemplo las fábricas de Lodosa (Sulfato de Sosa), Munilla y Enciso (Paños) Quel y Autol (Destilerías de aguardiente) y Arnedillo (Caleras y Yeserías) ${ }^{7}$.

\section{4.}

5. Sánchez Lozano, R. "Memorias de Comisión del Mapa Geológico de España. Descripción Física, Geológica y minera de la provincia de Logroño" Madrid, 1894, pág. 454.

6. Sobre este mismo tema abunda Casariego "E1 marqués de Sogadelos o los comienzos del industrialismo capitalista en España" Oviedo, 1974.

7. Sánchez Lozano, R. Op. cit., pág. 457. 
Pero esta demanda, circunscrita a las necesidades escasas de una comarca reducida, no permitían ni la capitalización de las empresas ni su modernización en ningún orden, de ahí que la cima de su producción se alcanzase en 1867 con 12.433 Qm. de mineral para la venta.

Esto no significa que los únicos problemas mineros de la zona fueran de tipo comercial o financiero: tanto en Préjano como en Turruncún el mineral aparecía dislocado por fallas y por contactos anormales con los conglomerados del terciario, y los mineros trabajaban a ciegas al carecer las empresas de estudios geológicos serios. En este contexto, no es de extrañar que la actividad minera languideciese y desapareciera sin llegar a conocerse, a ciencia cierta, las posibilidades que ocultaba Peña Isasa.

A tenor de los análisis hechos por los técnicos llegados a la zona, la calidad de los carbones es rentable, como se refleja en el cuadro adjunto.

\section{CUADRO N..$^{\circ} 1$ RIQUEZA DE LOS CABONES DE PREJANO Y TURRUNCUN}

\begin{tabular}{|c|c|c|c|c|}
\hline & PREJ $t$ & NO & & URRUNCUN \\
\hline & (1) & (2) & (3) & (2) \\
\hline & La More & & Sta. Isabe & \\
\hline & $\%$ & $\%$ & $\%$ & $\%$ \\
\hline CARBONO FIJO & 53,50 & $50,-$ & 46,21 & 41,50 \\
\hline SUBST. VOLATILES & $40,-$ & $35,-$ & $43,-$ & 3,50 \\
\hline CENIZAS & 6,50 & $15,-$ & 10,79 & $55,-$ \\
\hline TOTAL & $100,-$ & $100,-$ & $100,-$ & $100,-$ \\
\hline CALORIAS & 6.380 & 6.110 & 5.190 & 6.640 \\
\hline
\end{tabular}

FUENTE: Sánchez Lozano, R. "Memorias de la Comisión..." p. 456

(1) Ensayo hecho en la Escuela especial de Minas de Madrid

(2) Oriol, R. "Carbones minerales de España" 1874

(3) Ensayo hecho en Cartagena sobre labores antiguas. 1894

Sobre los yacimientos de Préjano, el ingeniero Vernier escribió una pequeña memoria que resumimos a continuación. 
Las capas de mineral se hallan en una franja de no más de 250 metros de anchura por 8 kilómetros de longitud, son en total unas veinte y su espesor oscila en torno a los 50 centímetros. La calidad del mineral es buena, los resíduos de cenizas normales y el coque producido resultará muy "a propósito para los caminos del hierro y para los metalúrgicos". Tras el convencimiento, de que, por su riqueza en gas, su uso será muy aprovechable para la industria, concluye, sin rubor alguno, que "ésta constituye probablemente, la primera hulla de España para esta clase de aplicación y para el uso doméstico" $"$.

Junto a estos carbones, aparece un carbonato de hierro litoide en forma de riñones y si, según los pronósticos de $\mathrm{H}$. Vernier, la riqueza del mineral avala la construcción de muchos altos hornos "esta circunstancia permitirá construir sobre este punto un centro de producción de hierro que, con respecto a la buena salida de sus produtos, hallará difícilmente un rival en España".?

Con toda sencillez el ingeniero compara los yacimientos de Préjano con los de Dutley, asegurando que "lo que aquellas cuencas caboníferas son para Inglaterra, podrá ser ésta para la España el día que demuestre bien la abundancia del mineral (hipótesis) y el camino del hierro proyectado (de hecho llegó a haberlo, pero casi no se utilizó) por cuyas vías se podrá, facilitando un transporte económico, llevar estos productos hasta las orillas del Mediterráneo y demás puntos de la península"10 .

A pleno galope de euforia, calcula que podrán beneficiarse seis millones de toneladas sin apenas "trabajos de apuramiento" , creándose una red de consumo en un radio de ocho leguas, pues se hallan cerca cuatro o cinco centros de manufacturados de paños comunes, teniendo en cuenta, además, que "en Logroño, Tudela, Calahorra y en las riberas del Ebro se hace una fabricación de aguardiente bastante grande"1

8. Martínez Alcibar, A. "Memoria de las minas de carbón-piedra existentes en los distritos municipales de Préjano, Turruncún y Villarroya" 1858. En el mismo folle to de 26 páginas aparece una "Relación sobre las minas de Préjano" del año 1854, por el ingeniero Vernier.

9. Ibid. pág. 6 .

10. Ibid. pág. 7 .

11. Ibid. pág. 7.

12. Ibid. pág. 8. 
TOMAS FRANCO ALIAGA

\section{Turruncún}

La otra zona rica en hulla es la de Turruncún y Martínez de Alcibar $^{13}$ cree que su explotación no entraña excesivas dificultades, pues las capas están verticales y se pueden atacar desde la parte baja de la montaña con pequeñas galerías.

Piensa, y con razón, que el mayor problema estribará en el transporte, si bien por entonces (1858) ya se estaba construyendo la carretera de El Villar a Arnedo que reducía el camino de carros a sólo legua y media.

Una vez puesto el carbón en pista llana, se extenderá rápidamente "no sólo a puntos distantes en Castilla, sino también a muchos de Navarra, donde la carencia de combustible vegetal hará indispensable el uso del carbón de piedra"14 .

No cree que exista ninguna pega sobre el consumo del mineral porque hay un contrato escriturado con la Compañía de minas de sosa de España "en la que resulta un consumo diario respetable". Además, se cuenta con la solicitud de todos los fabricantes de aguardiente, jabones "y demás que se hallan establecidos en varios puntos del litoral que no desconocerán las ventajas que tendrán con el consumo de este carbón"15.

En fin, que con el tiempo, "es de esperar que la aplicación se haga extensiva a la mayor parte de los objetos que reclaman este combustible"16. Las mejores esperanzas sin embargo del autor se centran en el proyecto de construcción del ferrocarril Zaragoza-Bilbao, pues, si se monta una fábrica de beneficio para el hierro, aparte de proporcionar a las máquinas el carbón preciso, los productos de aquélla servirían para el tendido de las vías y cuantos útiles se precisaran para su mantenimiento posterior ${ }^{17}$.

En 1870 se inauguró la línea férrea que unía Zaragoza con Bilbao, pero en ningún momento se proyectó ubicar una ferrería en las inmediaciones de Turruncún poque quedaba a trasmano, no se tenía certeza alguna sobre la abundancia de carbón ni tampo el hierro aparecía al ritmo de los deseos de nuestros autores.

13. Nota 8 .

14. Martínez Alcibar, "Memoria sobre las minas..." pág. 10.

15. Ibid. pág. 10 .

16. Ibid. pág. 10.

17. Ibid. pág. 11 . 


\section{CUADRO N. ${ }^{\circ} 2$. PRODUCCION DE HULLA EN LAS PRINCIPALES PROVINCIAS ESPAÑOLAS}

Y EN LOGROÑO (1861-1890)

(En toneladas)

\begin{tabular}{|c|c|c|c|c|c|c|}
\hline PERIODOS & ESPAÑA & ASTURIAS & $\%$ & CIUDAD REAL \% & CORDOBA \% & GERONA \% \\
\hline $\begin{array}{l}1861-1865 \\
1866-1870\end{array}$ & $\begin{array}{l}1.941 .880 \\
2.605 .990\end{array}$ & $\begin{array}{l}1.428 .690 \\
1.855 .800\end{array}$ & & $\begin{array}{l}--- \\
---\end{array}$ & $\begin{array}{r}65.920 \\
268.800\end{array}$ & $\begin{array}{l}13.672 \\
13.100\end{array}$ \\
\hline TOTAL & 4.547 .870 & 3.284 .490 & $(72,2)$ & --- & $334.720(7,3)$ & $26.772(0,5)$ \\
\hline $\begin{array}{l}1871-1875 \\
1876-1880\end{array}$ & $\begin{array}{l}3.307 .180 \\
3.516 .090\end{array}$ & $\begin{array}{l}1.940 .380 \\
1.956 .050\end{array}$ & & $4 . \overline{500}$ & $\begin{array}{l}715.560 \\
705.460\end{array}$ & $\begin{array}{l}22.939 \\
23.391\end{array}$ \\
\hline TOTAL & 6.823 .270 & 3.896 .430 & $(57,1)$ & 4.500 & $1.421 .020(20,8)$ & $46.330(0,6)$ \\
\hline $\begin{array}{l}1881-1885 \\
1886-1890\end{array}$ & $\begin{array}{l}5.253 .810 \\
4.879 .515\end{array}$ & $\begin{array}{l}2.316 .370 \\
2.510 .440\end{array}$ & & $\begin{array}{l}106.370 \\
221.055\end{array}$ & $\begin{array}{r}1.005 .020 \\
918.915\end{array}$ & $\begin{array}{l}192.396 \\
232.458\end{array}$ \\
\hline TOTAL & 10.133 .325 & 4.826 .810 & $(47,6)$ & $327.425(3,2)$ & $1.923 .935(18,9)$ & $442.854(4,3)$ \\
\hline
\end{tabular}

FUENTE: ESTADISTICA MINERA (Elaboración propia) 
CUADRO N. ${ }^{\circ}$ 2. PRODUCCION DE HULLA EN LAS PRINCIPALES PROVINCIAS ESPAÑOLAS

Y EN LOGROÑO (1861-1890)

(En toneladas)

\begin{tabular}{|c|c|c|c|c|c|}
\hline PERIODOS & LEON & PALENCIA & SEVILLA & LOGROÑO* & $\%$ \\
\hline $1861-1865$ & 31.002 & 356.620 & 34.970 & 3.566 & \\
\hline $1866-1870$ & 17.490 & 413.630 & 32.490 & 2.540 & \\
\hline TOTAL & $48.492(1,0)$ & $770.250(16,9)$ & $67.460(1,4)$ & 6.106 & 0,13 \\
\hline $\begin{array}{l}1871-1875 \\
1876-1880\end{array}$ & $\begin{array}{l}24.395 \\
38.976\end{array}$ & $\begin{array}{l}549.760 \\
690.060\end{array}$ & $\begin{array}{l}56.790 \\
93.830\end{array}$ & $\begin{array}{r}825 \\
1.916\end{array}$ & \\
\hline TOTAL & $63.371(0,6)$ & $1.239 .820(18,1)$ & $150.620(2,2)$ & 2.741 & 0,04 \\
\hline $\begin{array}{l}1881-1885 \\
1886-1890\end{array}$ & $\begin{array}{l}62.272 \\
67.290\end{array}$ & $\begin{array}{r}1.198 .750 \\
514.310\end{array}$ & $\begin{array}{l}368.047 \\
405.965\end{array}$ & $\begin{array}{r}2.344 \\
326\end{array}$ & \\
\hline TOTAL & $129.562(1,2)$ & $1.713 .060(16,9)$ & $774.012(7,6)$ & 2.670 & 0,02 \\
\hline
\end{tabular}

FUENTE: ESTADISTICA MINERA (Elaboración propia * Los años $1870,1871,1872$ y 1888 no registraron producción. 


\section{Volumen de la Producción}

Ya se ha visto cómo la demanda del carbón de Peña Isasa se circunscribía a un ámbito comarcal muy reducido. en el que las industrias, además, carecían de relieve.

¿Pero qué representaba la producción riojana en el contexto nacional o comparada con otras provincias productoras? La respuesta la tenemos en el cuadro n.$^{\circ} 2$ del que deducimos que La Rioja desempeñó un papel meramente testimonial con unos porcentajes sobre el total nacional de 0,$13 ; 0,04$; y del 0,02 por ciento, respectivamente, para las décadas que van de 1860 a 1890.

Pero si la incidencia del carbón riojano en la producción nacional era inapreciable, aún resulta más sintomático que ni siquiera pudiese atender la demanda provincial por las dificultades del transporte que lo encarecía a límites prohibitivos.

\section{Precios del carbón Riojano}

Poseemos algunos datos sobre los precios del carbón en Préjano y Turruncún en el año 1865 que recogemos en el cuadro n. ${ }^{\circ} 3$.

CUADRO N. ${ }^{\circ}$ 3. PRECIO DEL CARBON RIOJANO (1865)

(Pesetas por tonelada)

DESTINO

A BOCA - MINA
MUNILLA - ENCISO
QUEL - AUTOL

\section{CALIDAD}

$\begin{array}{rcc}\text { Superior } & \text { Casquetoso } & \text { Menudo } \\ 21,16 & 16,27 & 10,85 \\ +10- & +10-- & +10- \\ +5- & +5-- & +5-\end{array}$

FUENTE: Sánchez Lozano, R. "Memorias de la Comisión..." p. 457

A tan sólo unos cuantos kilómetros (Munilla o Enciso) el carbón se ponía en 31,16 ptas. En Logroño o Tudela, los precios debían ser astronómicos. Frente a ello, el carbón asturiano en San Sebastián costaba 28,40 ptas. la tonelada; en Bilbao 24,64; en La Coruña 27,26; en Cádiz 35,81 y en Adra 34,54. Es decir, que sale más caro el carbón de Préjano en Munilla que el de Asturias en La Coruña o San Sebastián. Incluso el carbón inglés, de calidad 
incomparable, era desembarcado en La Coruña a tan sólo 94 céntimos más caro que el de Préjano en Enciso ${ }^{18}$.

Con poco esfuerzo se comprende que, en estas condiciones, la minería riojana no tenía ningún futuro y todas las elucubraciones, hipótesis o deseos al margen de estos datos objetivos son ganas de perder el tiempo o de volver la espalda a la realidad.

\section{La Minería del Hierro}

\section{Situación del pais}

El análisis comparativo de cualquier fenómeno permite situarlo en sus verdaderos límites, de ahí que antes de estudiar el desarrollo de la minería del hierro en La Rioja, dediquemos unas líneas a describir la situación general del país en dicha actividad.

Cuando, en la segunda mitad del siglo XIX, el librecambismo dominante favoreció el control de la minería y de la construcción de los ferrocarriles por el capital extranjero, España poseía una gran riqueza de mineral de hierro, repartida por varios puntos del país.

La situación económica del Occidente europeo, en pleno auge industrial decimonónico, convierte a nuestra tierra en una de las zonas más codiciadas, situación que perdurará hasta que aquél saque un sustancioso provecho y descubra nuevos y más ricos yacimientos en otros continentes.

Inglaterra, Francia, Alemania y Bélgica exigen cantidades cada vez mayores de materias primas y España se los brinda en abundancia y a buen precio. Sólo a finales del siglo, tras imponerse las corrientes proteccionistas, se pudo aplicar la riqueza minera en beneficio propio.

Durante los decenios del saqueo, pues tal era la situación denunciada por numerosos industriales desde el interior, España iba a la cabeza de Europa en cuanto a producción del mineral; sin embargo "su producción siderúrgica era sólo el 10 por ciento de la

18. Recordemos, eso sí, que el transporte entre estos pueblos distantes unos 30 kilómetros, se hacía a lomos de caballería, con unos 100 kilos de media por animal. 
belga y el 0,7 por ciento de la inglesa"19.

Las principales cuencas mineras estaban en Vizcaya, Santander, Guadalajara, Teruel, Cataluña y Almería. Vizcaya fue, desde el primer momento, el mayor productor y exportador. FLINN asegura que, en 1912, de las 74 compañías británicas dedicadas a los asuntos mineros en España, la mayor parte estaban afincadas en esta provincia y de los 180 millones de toneladas que Inglaterra importó de 1871 a 1914 , el 80 por ciento, o sea, 144 millones, llegaron de la Península ${ }^{20}$.

\section{CUADRO N..$^{\circ}$ 4. PRODUCCION Y EXPORTACION DE HIERRO (1860-1900) (En millares de toneladas)}

\begin{tabular}{|c|c|c|c|c|c|}
\hline AÑNOS & PRODUC. & $\%$ increm. & Export. & $\%$ increm. & o vol. exp. \\
\hline 1860 & 173 & $\ldots$ & -- & $\ldots$ & -- \\
\hline 1865 & 191 & 10,4 & -- & -- & $\ldots$ \\
\hline 1870 & 436 & 128,2 & 253 & -- & 58 \\
\hline 1875 & 520 & 19,2 & 336 & 32,8 & 64,6 \\
\hline 1880 & 3.565 & 585,5 & 2.932 & 772,6 & 82,2 \\
\hline 1885 & 3.933 & 10,3 & 3.311 & 12,9 & 84,1 \\
\hline 1890 & 6.546 & 66,4 & 4.795 & 44,8 & 73,2 \\
\hline 1895 & 5.514 & 15,7 & 5.100 & 6,3 & 92,4 \\
\hline 1900 & 8.675 & 57,3 & 7.800 & 52,9 & 89,9 \\
\hline
\end{tabular}

FUENTE: Sánchez Ramos, F. “La economía siderúrgica...” p. 181 y 221 Vicens Vives, J. “Historia económica..."p. 601 (Elaboración propia).

A excepción de los años 1890 y 1900, el incremento de la exportación supera con creces al de la producción. Pero el verdadero problema está en el volumen exportado, que arroja una media del 77,7 por ciento durante el último tercio del siglo XIX, alcanzando, en algún momento, la casi totalidad del mineral extraído.

19. Informe sobre el derecho diferencial de bandera sobre aduanas exigibles a los hierros, al carbón de piedra y los algodones, presentada al Gobierno de su Magestad por la Comisión nombrada al efecto en Real Decreto del 10 de Noviembre de 1865, Tomo II, pág. 341.

20. FLINN, M. W. “Acero británico y mineral Español: 1871-1914”. Rev. de Economía Política, Vol. VIII, n. ${ }^{\circ} 2$, pág. 607 y ss. 
En 1895 llegó a exportarse el 92,4 por ciento, lo que, si bien suponía unos ingresos sustanciosos para Vizcaya, base de su rápida industrialización ${ }^{21}$, no es menos cierto que fue a costa de privar al país de una industria básica propia. Ante nuestras necesidades de herramientas, material ferroviario y de construcción, etc. no contábamos con más opciones que reprimirlas, ahogando cualquier posibilidad de desarrollo o acudir a la importación, siempre costosa y depauperante en todos los órdenes.

Del año 1849 a 1868 , se importaron 305 embarcaciones que representaron el 99 por ciento de las necesidades de nuestra marina $^{22}$ y en 1861 las compañías extranjeras concesionarias de la construcción de los ferrocarriles introdujeron "legalmente" en el país 27.164 palas de hierro con mangos de madera ${ }^{23}$. Digo "legalmente" porque en el artículo $20, n{ }^{\circ} 5$ de la Ley General de 3 de junio de 1855 podemos leer que se concederá a tales compañías, entre otras muchas prebendas, "el abono, mientras la construcción y diez años después, del equivalente a los derechos marcados en el arancel de aduanas y de los faros, portazgos y barcages que deban satisfacer las primeras materias, efectos elaborados, instrumentos, útiles, máquinas", etc... ${ }^{24}$.

Basten estos ejemplos para ilustrar el estado de postración de nuestra siderurgia, la política colonizadora de las compañías extranjeras y la cretina interpretación del librecambismo por nuestros políticos. Todo ello levantó las iras de numerosos fabricantes de productos férricos que, ya en 1862, arremetieron contra los privilegios dados a los extranjeros a costa de su propio desarrollo, en este caso el del país. "La industria nacional ferrera -afirmaban- ha visto reducido por esta franquicia a la tercera parte del consumo de su mercado y no ha podido tener el desenvolvimiento a que estaba llamada. Lo que debía ser motivo de prosperidad y garantía de su

21. Lequerica, J.F. "La actividad económica..." 1956 dice que desde 1865 se han sacado del País Vasco 265 millones de toneladas, con unos ingresos medios de 100 millones de pesetas anuales lo que permitió" la constitución de las por tantos conceptos admirables Industrias y Banca Vascas" pág. 601.

22. Alzola, B. "Estudio relativo a los recursos de que la industria nacional dispone para las construcciones y armamentos navales" Madrid 1886, pág. 231.

23. J. "Ensayos sobre la economía española a mediados del siglo XIX" Madrid, 1970, pág. 209.

24. "Colección legislativa de ferrocarriles o recopilación de las leyes, reglamentos, instrucciones, decretos, reales órdenes y circulares expedidas para la explotación de las vías férreas desde 1855 hasta la fecha" Albacete, 1877, pág. 6. 


\section{MINERIA RIOJANA EN EL SIGLO XIX}

vida, ha sido causa de su decadencia y peligro de su muerte"25.

\section{El monte San Lorenzo, nibelungo de hierro}

La historia de la minería riojana es de larga memoria, pero de escasos resultados prácticos. Algunos estudiosos de la tierra han dado en confundir los deseos con la realidad y en sus escritos se mezclan las noticias de hallazgos humildes con las intuiciones de riquezas fabulosas.

Pero dejemos explayarse a Diego Ochagavía: "Minúscula y apenas trascendente ha sido la explotación de los filones metálicos que en el subsuelo riojano duermen improductivos e inútiles, no obstante su abundancia" ${ }^{26}$. La ubicación de tales riquezas se extiende por la Sierra de la Demanda donde "luce el monte de San Lorenzo, en cuyas faldas, sembrando sierras y hondonadas desde Ezcaray a las Viniegras, yace intrascendente e inane la más rica bolsa férrica de España que, en la imposibilidad de germinar y florecer como, al llegar cada primavera lo hace la capa de su cobertura" (...) espera "como nibelungo negligente" que llegue el ferrocarril para abrir su "potente corazón" y mostrar "tan quimérica reserva"27.

La larga cita, aunque de estilo trasnochado, no carece de encanto poético y resume la postura adoptada por otros autores sobre el mismo tema.

Una vez y otra vez se insiste en que las riquezas mineras de La Rioja "son amplísimas", que se han hecho "análisis concienzudos" y que del estado de postración actual son culpables la desidia de las autoridades, la poca visión de nuestros hombres de negocios, y la falta de unos transportes adecuados.

La historia de la "quimérica reserva" de hierro en la zona de la Viniegras es la siguiente: Jorda Padro publicó en 1893: "Lo que reclama atenta y circunstanciada recomendación es la juntamente renombrada cuenca de las Viniegras. Desde Ventrosa a Huertas

25. "Observaciones que varios fabricantes del hierro hacen sobre la exposición presentada a S.M. con fecha 15 de diciembre de 1862 por la asociación para la Reforma de Aranceles" Madrid 1862, pág. 8.

26. Ochagavía, D. "Notas para historia minero-fabril riojana” Rev. Berceo, núms. 21-22, Logroño, 1951-2, pág. 469.

27. Ibid. pág. 470 . 
de arriba va comprendida una enorme mole de la aproximada cubicación de 100.000.000 de toneladas a la vista' ${ }^{\text {'28 }}$.

Sánchez Lozano, refiriéndose al mismo asunto señala con cierta timidez que "los datos de que disponemos son insuficientes para fijar de una manera siquiera aproximada la cantidad de mineral contenido en estos criaderos: no falta sin embargo, quien afirma que la cubicación a la vista arroja 100 millones de toneladas"29 . Es más que probable que se refiriese a Jorda, cuyo libro apareció un año antes.

Si bien ambos autores cubicaron a placer el volumen de los yacimientos, hay que reconocerles el carácter nada resolutivo que dieron a sus palabras. Para Ochagavía, en cambio, la presencia y la cuantía del mineral no ofrecen la menor duda, pues se hallan respaldadas por la opinión de algunos técnicos ${ }^{30}$. García Prado, va más lejos y nos da una magistral interpretación de por qué no se explotan los yacimientos "en la intensidad de que su riqueza cabría esperar". No se debe a razones coyunturales de la demanda, ni a la falta de capitales, ni a la carencia de medios técnicos adecuados ni siquiera a la presencia de rutas escarpadas sólo utilizables por mulos de carga. E1 piensa que "La Rioja no necesitó de sus riquezas minerales para tener vida próspera, se consideró feliz con el producto de sus campos y no se sintió acuciada a buscar la prosperidad por otros caminos"31.

Nada, en el resto del artículo, nos permite deducir que el autor se tome el asunto con ligereza o con humor. El sabrá cuándo y cómo La Rioja prefirió masivamente la felicidad y el bucolismo agrario a otras posibilidades de desarrollo de tipo industrial.

Pero no acaban aquí las aportaciones de nuestros autores. Dos viajeros cualificados por su profesión y con alma de investigadores, D. José Vicente Pereda, cura párroco de Santa Eulalia y D. Ignacio Aguirre, empleado en el Real Servicio, recorren la zona camerana con el propósito de ofrecer a su Magestad el resultado de sus investigaciones mineras. Los hallazgos no se hicieron esperar y "personas

28. Jorda Padro, J. "Logroño económico" Logroño 1893, pag. 106 (E1 subrayado es del autor).

29. Sánchez Lozano, R. "Memorias de la comisión..." pág. 425.

30. Ochagavía, D. "Notas para la historia..." pág. 493.

31. García Prado, J. “Minería en La Rioja: un viaje de fines del siglo XVIII” Berceo (Rev.) n. ${ }^{\circ} 36$ - Logroño 1955, pág. 263. 
principales de la villa de Anguiano dicen que en el sitio de la Obrilla, contiguo a la Iglesia Parroquial, por la banda de arriba, por donde pasa el camino que va de esta villa a la de Nieva, habían visto correr repetidas veces azogue, en su propia figura sobre la tierra, a manera de una cuerda, que a las veces se romía o dividía por varias partes en una infinidad de globulillos redondos" 32 .

Peregrinan hasta el lugar y la contemplación del fenómeno les lleva a la conclusión de que "sería dificultoso dexar de producir el metal de azogue en una mina de las más cuantiosas del orbe"33. Hasta tal punto les parece importante el yacimiento que no dudan en compararlo y aun ponerlo por delante de las minas de Almadén.

En opinión de Sánchez Lozano "dieron crédito a las versiones de los naturales del país, que aseguraban haber visto el azogue nativo en varios puntos, $\mathrm{y}$ con tales fundamentos redactaron su manuscrito lleno de optimismo" 34 .

Al final del viaje presentaron 56 muestras de las que, una vez analizadas, sólo cuatro merecieron cierta atención.

Entre éstas, resultan curiosas las muestras de esmeraldas semejantes a las de Santa $\mathrm{Fe}$, recogidas en el Barranco de Antoñanzas en Arnedillo. Lo más probable es que, debido a la proximidad del criadero de cobre, se tomase como piedra preciosa el cobre dioptasa "cuya forma y hermoso color verde son semejantes a los de la esmeralda"35.

Han pasado muchos años y ya no se ha vuelto a hablar de las esmeraldas del Barranco de Antoñanzas en Arnedillo.

32. "Descripción del viaje..." Biblioteca Nacional, secc. manuscritos números 470-97. 1793. Sánchez Lozano fecha de este manuscrito, pormenores de su localización y copias en 1787.

Casariego, (E1 marqués de Sagadelos..." pág. 137) Habla del mismo presbítero en términos elogiosos "merece especial y honrosa mención en la historia de la minería Asturiana... Hombre de gran afición a la geología... animó y dirigió muchos trabajos de gran utilidad".

Destacamos esta opinión para hacer justicia a un hombre que si en Asturias tuvo fama de gran conocedor de la minería, en la Rioja sus previsiones no dieron ningún resultado positivo.

33. Ibid. pág. 13.

34. Sánchez Lozano, op. cit., pág. 428. Elías, L.V. Cree que el informe está redactado "con más ingenuidad que conocimientos científicos". Premios Rioja de Periodismo" La Rioja Insólita”' Diput. Provincial. 1976, pág. 53.

35. Sánchez Lozano, “Memorias de la Comisión..." pág. 427. 


\section{Localización y producción}

Los yacimientos de carbón, según hemos visto, se extienden por la zona Este de la provincia, entre los cursos altos de los ríos Cidacos y Alhama; el hierro, en cambio, ocupa una amplia superficie a ambos lados del río Najerilla, entre la Sierra de la Demanda y Camero nuevo, alcanzando la cuenca del Glera por el oeste.

En dos zonas del área delimitada, aparece el mineral del hierro con cierta profusión.

La primera se extiende por los términos de Ezcaray, Tobía y Matute, cruza el Najerilla y llega hasta Anguiano describiendo una amplia curva a los pies de la Sierra de San Lorenzo por el Norte. Junto a las aldeas de San Antón y Azarrulla, hacia la cabecera del río Glera, aún pueden contemplarse las labores practicadas a cielo abierto.

Las vetas no son uniformes ni continuas en esta primera zona, lo que ha originado un laboreo selectivo y apresurado "sin tener en cuenta más que el lucro inmediato"36, favorecido por la topografía, pues numerosas vetas eran fáciles de atacar al aparecer colgadas sobre los barrancos. La riqueza del mineral es baja, oscilando entre un 30 y un 32 por ciento.

La segunda franja se inicia en Brieva, continúa hasta Ventrosa y Viniegra de Abajo, y de aquí se ramifica por el Sureste hacia Viniegra de Arriba y por el Noreste hasta Villavelayo y Canales, en la margen izquierda del Najerilla.

En ambas zonas predominan los óxidos y el carbonato de hierro que corresponden a las especies hematites parda y roja.

Para Jordá, "las sendas escabrosas e infranqueables en buena parte del año son motivo de que su explotación sea sumamente difícil". Pero convendría recordar que estos obstáculos no hubieran sido insuperables si la riqueza y la abundancia del mineral hubieran merecido la pena.

Como resultado de todo esto, en el cuadro $n .{ }^{\circ} 5$ vemos que la producción riojana, dentro del contexto nacional y aun comparada con algunas provincias mineras, era mínima.

36. Ibid. pág. 437. 
MINERIA RIOJANA EN EL SIGLO XIX

CUADRO N. ${ }^{\circ}$ 5. PRODUCCION DE ALGUNAS PROVINCIAS Y LOGROÑO (En toneladas)

\begin{tabular}{|c|c|c|c|c|c|c|c|c|c|}
\hline Año & España & Vizcaya & $\%$ & Santan. & $\%$ & Almería & $\%$ & Logroño & $\%$ \\
\hline & 520.000 & 245.000 & 47,1 & 7.000 & 10,9 & 60.000 & 11,5 & 1.321 & 0,2 \\
\hline & 3.565 .000 & 2.683 .000 & 75,2 & 75.000 & 2,1 & 88.500 & 2,4 & 2.103 & 0,05 \\
\hline & 3.933 .000 & 3.311 .000 & 84,1 & - & - & -- & & 645 & 0,01 \\
\hline
\end{tabular}

FUENTES: Buguera, F.G. "Histoire Contemporaine d' Espagne (1789-1950)" OPHRYS, París 1953, p. 305 (Cit. por Lacomba, "Introducción a la Historia..." p. 169.

Sánchez Lozano, R. "Memorias de la comisión..." p. 450-31.

(Elaboración propia).

Existían tres fábricas ubicadas, una en Tobía (La Gloria), otra en San Millán de la Cogolla (Infierno) y la tercera en Azarrulla (Buenaventura), aldea de Ezcaray.

Los tres establecimientos utilizaban carbón vegetal, principalmente de haya, y como fundente las escorias resultantes de la afinación. Los productos eran muy apreciados por su calidad en Burgos, Valladolidad y Zamora, donde competían en precio con los vizcaínos.

"La Gloria" inició la fabricación de acero en 1877, y se mantuvo abierta hasta 1885, año en que las dificultades fueron insuperables: el carbón vegetal debían traerlo desde Alava e incluso el mineral de hierro, en los últimos tiempos, procedía de Ollargan (Bilbao) ${ }^{37}$. Su cierre arrastró a la otra fábrica de San Millán de la Cogolla.

"La Buenaventura", posteriormente denominada "Numancia", aguantó con grandes dificultades hasta 1893.

Tal fue la historia de estos tres establecimientos férricos que permanecieron abiertos desde 1861 a 1893 . En estos 33 años, muchos de ellos sin actividad alguna, se fabricaron 14.977 toneladas de hierro colado y 11.654 de hierro forjado, a una media de 807 toneladas de producción anual.

\section{Epilogo}

La I Guerra Mundial supuso un brusco acelerón en la demanda

37. Sánchez Lozano, op. cit., pág. 441 . En 1882 se trajeron a la fábrica de Tobía 481 toneladas "con no poco gasto". 
de materias primas por parte de los países beligerantes. Las minas de carbón riojanas dependían mayoritariamente del capital francés y su explotación se llevó a cabo "de modo anárquico y discontinuo y solamente para suplir las deficiencias de las explotaciones de su país"38.

Terminado el conflicto mundial, nuestra minería se estabiliza y aun desciende por la entrada del carbón inglés nuevamente y por los efectos negativos de la Gran Depresión.

Al llegar la República, las cooperativas obreras dan nuevo auge a la producción ${ }^{39}$, pero el gran salto adelante se llevó a cabo durante la política de autarquía del régimen franquista. Los 6,9 millones de toneladas de media en el período de 1931-35, se conviertieron en 10,9 en el de $1945-45$ y en 14,7 en el de $1956-60^{40}$.

En La Rioja también se notó este crecimiento espectacular, pues en 1952, cénit en la historia de su minería, se produjeron 6.760 toneladas.

En el año 1967 se cerraron definitivamente las minas de carbón; las de hierro habían languidecido a finales del siglo pasado, según vimos, por las dificultades de extracción, la baja riqueza de su mineral y la topografía desfavorable.

Ojalá las esperanzas de D. Diego Ochagavía sean ciertas y llegue el día en que el San Lorenzo abra sus entrañas de rico y abundante mineral. Seguro que La Rioja sabría conjugar la atención a una agricultura, altamente especializada, con las exigencias de esta nueva fuente de riqueza. Ayudas interesadas no le faltarían.

38. Camara Oficial de Comercio e Industria de Logroño, memoria, 1943 pág. 119.

39. Tamames, R., "Estructura Económica..." pág. 262.

40. I.N.E. 
MINERIA RIOJANA EN EL SIGLO XIX

\section{BIBLIOGRAFIA}

ALZOLA, B., 1886: Estudio relativo a los recursos de que la industria nacional dispone para las construcciones y armamentos navales. Madrid.

BUGUERA, F.G., 1953: Histoire contemporaine d'Espagne (1789-1950). OPHRYS, París.

CAMARA OFICIAL DE COMERCIO E INDUSTRIA. Memoria Logroño, 1943.

CASARIEGO, J.E., 1974: El marqués de Sagadelos o los comienzos del industrialismo capitalista en España. Instituto de Estudios Asturianos. Oviedo.

COLECCION LEGISLATIVA “de ferrocarriles o recopilación de las leyes, reglamentos, instrucciones, decretos, reales órdenes y circulares expedidas para la explotación de las vías férreas desde 1855 hasta la fecha". Albacete, 1877.

ELIAS, L.V., 1976: La Rioja insólita en Premios Rioja de Periodismo. Diputación Provincial. Logroño.

FLINN, M. W., 1957: Acero británico y mineral español: 1871-1914. Rev. de Economia Política, Vol. VIII, n. ${ }^{\circ}$ 2, Madrid.

GONZALEZ PORILLA, M., 1977: El mineral de hierro español (1870-1914): su contribución al crecimiento económico inglés y a la formación del capitalismo vasco. Estudios de Historia Social, n. 1 , Madrid.

GARCIA PRADO, J., 1955: Minería en La Rioja: Un viaje de fines del siglo XVIII. Rev. BERCEO, n. ${ }^{\circ} 36$, Logroño.

GEORGE, P., 1970: Geografía económica, Ariel, Barcelona.

INFORME "Sobre el derecho diferencial de Bandera sobre aduanas exigibles a los hierros, al carbón de piedra y los algodones". T. II, Carbones, Madrid, 1887.

JORDA PADRO, J., 1893: Logroño económico . Logroño.

LACOMBA, J.A., 1972: Introducción a la historia económica de la España contemporánea, Guadiana, Madrid.

LEQUERICA, J.F., 1956: La actividad económica de Vizcaya en la vida nacional. Madrid.

MARTINEZ ALCIBAR, A., 1858: Memorias sobre las minas de carbón de piedra existentes en los distritos municipales de Préjano, Turruncún y Villarroya. Logroño.

NADAL; J., 1970: Ensayo sobre la economia española a mediados del siglo XIX. Madrid. 


\section{TOMAS FRANCO ALIGA}

OBSERVACIONES que varios fabricantes del hierro hacen sobre la exposición presentada a S.M. con fecha 15 de noviembre de 1862 por la Asociación para la Reforma de Aranceles. Madrid, 1862.

OCHAGAVIA, D., 1951-52. Notas para la historia minero-fabril riojana. Rev. Berceo núms. 21-22, Logroño.

ORIOL, R., 1864: Carbones minerales de España, Madrid.

SANCHEZ LOZANO, R., 1894: Memorias de la Comisión del mapa geológico de España. Descripción física, geológica y minera de la Provincia de Logroño. Madrid.

TAMAMES, R., 1978: Estructura económica de España. Guadiana de Publicaciones, Madrid.

VERNIER, 1858: Relación sobre las minas de carbón de Préjano. Logroño. 